\title{
Cryomethods for Biological EM Specimen Preparation
}

\author{
Kent L. McDonald
}

Electron Microscope Lab, University of California, Berkeley, CA 94720-3330

In this "Ask the Experts" session, we will discuss how low temperature techniques can be used to provide high resolution stuctural information about cellular fine structure. However, no one person can be an "expert" in all cryotechniques, which cover such diverse applications as: cryofixation, cryosubstitution, cryoTEM, cryoSEM, freeze-fracture, freeze-drying, low-temperature embedding, and immunolabeling of sucrose-infiltrated cryosections, just to name a few of the most obvious. Fortunately, there are resources in the literature where one can learn more about all these methods and more. As a guide for those interested in this subject, a list of references is included (Appendix) that should cover most of what a newcomer to cryotechniques needs to know to get started. This is a list of personal favorites and is not intended to be comprehensive. To introduce the subject, we will discuss cryofixation by high pressure freezing followed by freeze-substitution and embedding in resin. Looking at thin sections by transmission EM is the most familiar viewing mode for most people and can demonstrate quite nicely the advantages of cryotechniques over conventional methods.

What are the advantages of cryofixation? Cryofixation takes milliseconds instead of the seconds to minutes that are required when cells and tissues are fixed by immersion or perfusion in buffered fixatives such as glutaraldehyde and osmium. In general, cryofixed samples more accurately represent cellular ultrastructure than those processed by conventional methods. There are many ways to cryofix samples, but in this presentation, we will focus on high pressure freezing, the method that can accommodate the greatest variety of samples. In some applications of cryotechniques such as freeze fracture, cryoSEM, or cryoTEM (thin samples in vitrified water), the cryofixed samples are probably as near to their native state as is possible for EM imaging. For more conventional imaging by thin sections or non-cryoSEM, the samples still need to be chemically cross-linked and dehydrated. This is the process called freeze substitution.

What happens during freeze substitution? In freeze substitution, the water in cells is replaced, or "substituted" with an organic solvent, usually acetone. Freeze substitution typically starts at temperatures of $-78.5^{\circ} \mathrm{C}$ to $-90^{\circ} \mathrm{C}$ using dry ice or a temperature-regulating freeze substitution device cooled with liquid nitrogen, then the samples are slowly $\left(5-10^{\circ} \mathrm{C} / \mathrm{hr}\right)$ warmed to room temperature. During this process water molecules are removed without the extractions and distortions that typically occur during room temperature dehydration. With fixatives such as glutaraldehyde or osmium tetroxide in the freeze substitution medium you avoid the diffusion gradient problem of conventional processing because the fixatives diffuse through the cells while they are immobilized by low temperature. Cross-linking occurs rapidly as they are warmed up to progressively higher temperatures. In the presentation we will discuss simple and inexpensive ways to do freeze substitution using dry ice and an insulated container such as a Stryafoam box.

Who should use cryotechniques? The methods we will discuss are not necessarily for everyone. They are really for those who need to maintain the near-native arrangement of molecules within the cell and who will image them at high resolution. Anyone doing 3-D reconstructions by serial 
sections or tomography, for example, will be more comfortable knowing that the structural relationships they are imaging are probably accurate to within a few nanometers. Because there is much less extraction of soluble proteins during freeze substitution, these methods are also recommended for EM immunolabeling studies.

Appendix - Introduction to the Literature of Biological EM Cryotechniques.

General Background Reading

1. Robards, A. W., \& Sleytr, U. B. (1985) Low temperature methods in biological electron microscopy. in: Practical Methods in Electron Microscopy” (Ed. A. M. Glauert), Vol. 10, Elsevier, Amsterdam.

2. Gilkey, J. C. \&Staehelin, L. A. (1986) Advances in ultrarapid freezing for the preservation of cellular ultrastructure. J. Electron Microsc. Tech. 3, 177-210.

3. Kellenberger, E. (1987) The response of biological macromolecules and supramolecular structures to the physics of specimen cryopreparation. in: "Cryotechniques in Biological Electron Microscopy. " (Eds. Steinbrecht, R.A., and K. Zierold), Pp. 35-63, Springer-Verlag, Berlin.

4. Echlin, P. (1992) “Low-Temperature Microscopy and Analysis” Plenum Press, New York.

High Pressure Freezing

5. Moor, H. (1987) Theory and practice of high pressure freezing. in: "Cryotechniques in Biological Electron Microscopy” (Eds. R. A. Steinbrecht and K. Zierold), Pp. 175-191. Springer-Verlag, Berlin.

6. Dahl, R. \& Staehelin, L. A. (1989) High-pressure freezing for the preservation of biological structure: theory and practice. J. Electron Microsc. Tech. 13, 165-174.

7. Studer, D., Michel, M., \& Müller, M. (1989) High pressure freezing comes of age. Scanning Microscopy, S3:253-269.

8. Kiss, J.Z., \& Staehelin, L.A. (1995) High Pressure Freezing. In, "Rapid Freezing, Freeze Fracture, and Deep Etching" (Eds. N.J. Severs and D.M. Shotton), Pp. 89-104, Wiley-Liss, New York.

9. McDonald, K. (1999) High pressure freezing for preservation of high resolution fine structure and antigenicity for immunolabeling. Meth. Molec. Biol. 117:77-97.

10. D. Studer et al. (2001) A new approach for cryofixation by high-pressure freezing. J. Microsc. 203:285-294.

11. E. Shimoni and M. Müller (1998) On optimizing high-pressure freezing: from heat transfer theory to a new microbiopsy device. J. Microsc. 192:236-247.

\section{$\underline{\text { Freeze Substitution }}$}

12. Steinbrecht, R.A., \& Müller, M. (1987) Freeze Substitution and Freeze Drying. in:

"Cryotechniques in Biological Electron Microscopy. " (Eds. R.A. Steinbrecht, and K. Zierold), Pp. 149-172, Springer-Verlag, Berlin.

13. Hippe-Sanwald, S. (1993) The impact of freeze substitution on biological electron microscopy. Microsc. Res. Tech. 24: 400-422.

14. Nicolas, M.-T., \& J.-M. Bassot. (1993) Freeze substitution after fast-freeze fixation in preparation for immunocytochemistry. Micros. Res. Tech. 24:474-487. 